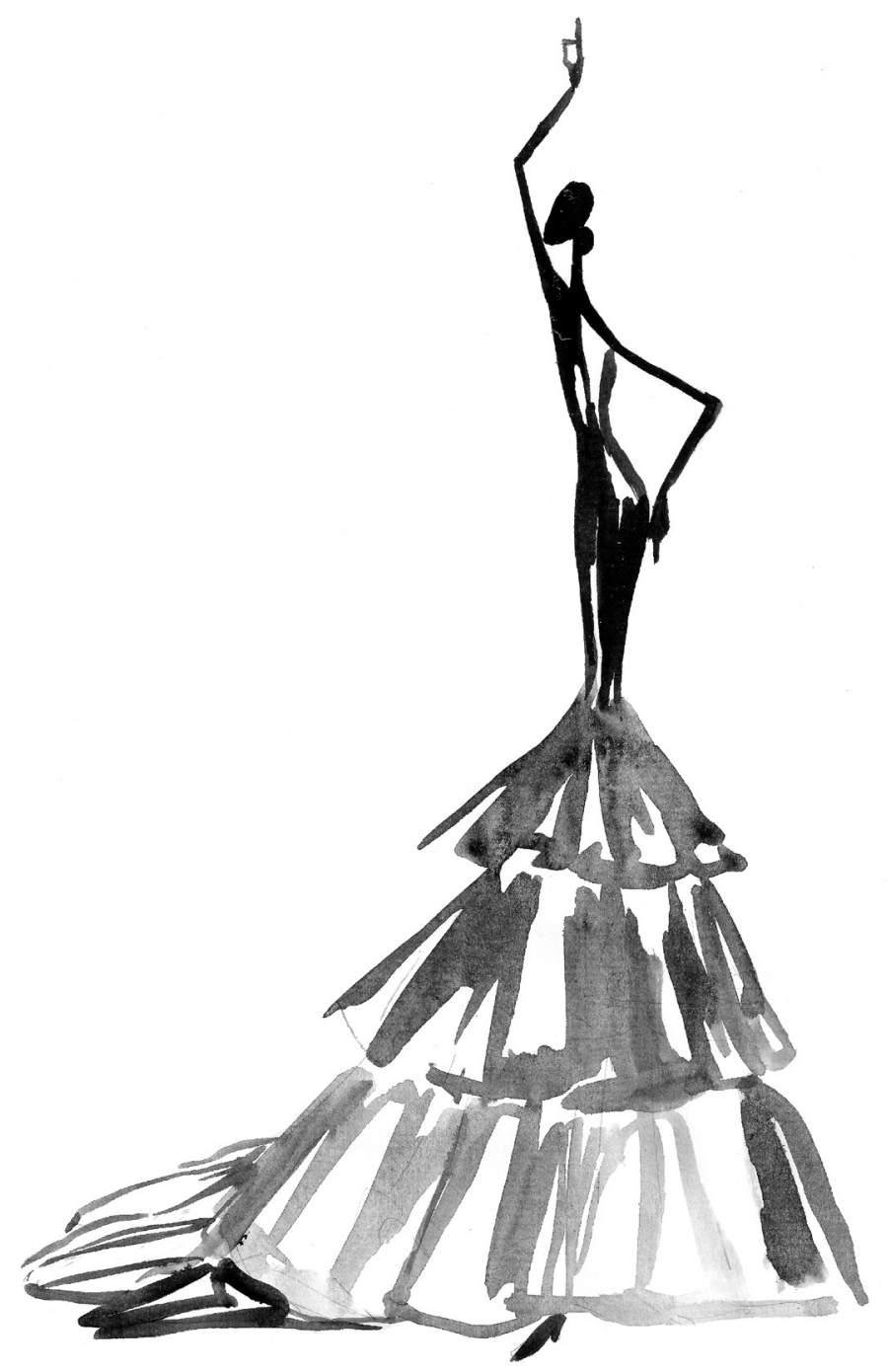

\title{
Prêmio Excelência Acadêmica Gilda de Mello e Souza
}

Maria de Fátima Mattos (CUML), Presidente da 9a Edição do Colóquio de Moda Maria Claudia Bonadio (UFJF), Vice-Presidente da 9a Edição do Colóquio de Moda

Foi em 2005, na cidade de Ribeirão Preto no interior de São Paulo, que aconteceu a 1a Edição do Colóquio de Moda.' Na ocasião o evento reuniu cerca de 50 comunicações orais, que tinham a moda, o vestuário e o figurino como temas principais. Naquele momento não era possível prever que o colóquio se consolidaria e se tornaria, no decorrer dos anos, o maior fórum para discussão de assuntos relativos à moda, de tal forma que, nas últimas edições, a média de trabalhos aprovados para apresentação no evento ficou em torno de 300.

0 crescimento do Colóquio de Moda gerou uma reestruturação em seu formato. Se nas primeiras edições os trabalhos eram divididos apenas em Sessões de Comunicação Oral, desde 2007 os trabalhos apresentados no colóquio são divididos por Grupos de Trabalhos². Passados sete anos da adoção dessa estrutura, é possivel notar que os grupos em questão acabaram por se firmar e alguns dos trabalhos apresentados devem parte do seu crescimento às discussões realizadas anualmente entre pares nesses grupos.

Diante da consolidação dos Grupos de Trabalho (GTs) e também da qualidade dos trabalhos apresentados em 2013 - muitos dos quais resultantes de pesquisas desenvolvidas em nivel de mestrado ou doutorado ou por pesquisadores doutores -, o comitê organizador do $9^{\circ}$ Colóquio de Moda considerou que era hora de ampliar a divulgação dos trabalhos apresentados no evento e criou o Prêmio Excelência Acadêmica Gilda de Mello e Souza, a partir do qual cada dupla de coordenadores de GT elege o 
melhor trabalho da área $^{3}$. Os nomes dos vencedores foram anunciados na cerimônia de encerramento do evento, que contou com o apoio financeiro da Coordenação de Aperfeiçoamento de Pessoal de Nível Superior (Capes) - na Universidade Federal do Ceará, em Fortaleza (CE) -, e os textos selecionados foram revisados e ampliados por seus autores e estão reunidos neste número especial da revista dObra[s].

Com o prêmio, além de contemplar os trabalhos por sua excelência acadêmica, realizamos ainda uma homenagem a Gilda de Mello e Souza (1919-2005), socióloga e autora do livro 0 espírito das roupas: a moda no século dezenove, publicado em 1987 pela Companhia das Letras. Obra resultante de sua tese de doutoramento defendida na Faculdade de Filosofia, Ciências e Letras da Universidade de São Paulo, em 1950. À época de sua produção, o trabalho foi

[...] considerado como fútil. Coisa de mulher. Na hierarquia acadêmica e científica da época, que presidia tanto a escolha dos objetos de estudo como a forma de exposição e explicação dos mesmos, a tese de Gilda constituiu uma espécie de desvio em relação às normas predominantes. (PONTES, 2006, p. 90)

As resistências não diziam respeito apenas ao tema, mas também à forma ensaística como o texto foi redigido e construído, posto que para sua elaboração Gilda de Mello e Souza utilizou fontes então consideradas pouco científicas, como fotografias, gravuras, pinturas e obras literárias do século XIX. Tal procedimento visto com ressalvas nos anos 1950 acabou por legar à obra um frescor que ainda hoje torna o texto atual. ${ }^{4}$ Pela importância e pela atualidade da obra para os estudos acadêmicos de moda no País, consideramos que eleger a socióloga e autora como patrona do prêmio seria uma singela forma de homenageá-la e igualmente agradecer por sua contribuição para os estudos acadêmicos sobre moda.

No intervalo que separa a defesa da tese de Gilda de Mello e Souza (e mesmo a publicação de seu livro) e o prêmio que a homenageia, os pesquisadores que elegeram a moda como objeto de estudo nem sempre encontraram facilidades, como bem aponta o filósofo francês Gilles Lipovetsky, que, em 1989, ${ }^{5}$ iniciava a apresentação do seu livro 0 império do efêmero: a moda e seu destino nas sociedades modernas com a máxima "A questão da moda não faz furor no mundo intelectual" (p. 9), tão pertinente na década de 1980. A partir da instauração do prêmio não temos dúvida em afirmar: hoje, a moda faz furor no mundo intelectual.

0 crescimento de um evento como o Colóquio de Moda, a ampliação dos fóruns de debate sobre o tema e a disseminação de publicações na área, além do número de teses e dissertações que tratam do assunto, iluminam essa realidade ${ }^{6}$. Os números disponibilizados pela Fundação de Amparo à Pesquisa do Estado de São Paulo (FAPESP) reforçam a impressão ${ }^{7}$. Nos últimos 20 anos, a FAPESP fomentou aproximadamente 100 projetos (entre publicação de livros, dissertações de mestrado, teses de doutorado, auxilio pesquisa, auxílio viagem e iniciação científica) que tinham a moda ou 0 vestuário como tema ${ }^{8}$.

Não só vem crescendo o número de trabalhos que tem a moda como tema, como essa expansão - que se deu a partir dos anos 1990 e se consolidou na primeira década do novo milênio - ocorre nas mais diversas áreas do conhecimento (BONADIO, 2010). Assim, a discussão acerca da moda vem avançando tanto em áreas de vocação acadêmica, como Ciências Humanas, Comunicação, Educação e Artes, como nas áreas ligadas à prática e ao mercado, como Design, Modelagem, Inovação, Processos Têxteis, entre outras.

Diante desse quadro, os trabalhos contemplados na $1^{a}$ Edição do Prêmio Excelência Acadêmica Gilda de Mello e Souza funcionam como um bom panorama para visualizar como a moda e o vestuário estão sendo abordados pelas pesquisas acadêmicas desenvolvidas em âmbito nacional nas diversas áreas do conhecimento.

Não só a moda faz furor no mundo intelectual, como aqueles que se dedicam a estudar tópicos relacionados à área vêm colocando em questão a organização do campo, como o artigo Estilista? Designer de moda... ou um designer de objetos do vestuário? premiado pelo GT Design de Moda: Teoria e Crítica, que se propõe a debater a nomenclatura dada aos profissionais criativos da área. Seriam eles estilistas, designers de moda ou designers de objetos do vestuário? Eis as questões que Deborah Chagas Christo e Alberto Cipiniuk buscam esmiuçar no texto. 
Ainda no que diz respeito aos profissionais que atuam no campo da moda, as modelos, ou as garotas que desejam ser modelos, é o tema abordado no artigo 0 processo de midiatização e o sonho de ser modelo, de autoria de Daniela Schmitz e apresentado no GT Moda, Mídia e Estilos de Vida.

A mídia também é o objeto do artigo de Carla Maria Camargos Mendonça premiado pelo GT Corpo, Moda e Comunicação. Em seu trabalho A experiência estética: $a$ revista Vogue e os blogs de moda e fitness a autora percorre dois dos principais meios de divulgação de moda, as revistas e os blogs de moda e fitness, com vistas a entender como a moda é ao mesmo tempo "tirânica" e veículo determinante na disseminação de padrões estéticos e imagens desejáveis em termos de aparência.

0 papel estético da moda é discutido igualmente no artigo Vestuário e cidades: percepções de mulheres cariocas em São Paulo, de Solange R. Mezabarba, premiado pelo GT Consumo de Moda. No texto, a autora questiona a importância das cidades no que diz respeito ao projeto estético pessoal de mulheres cariocas que se mudaram para a cidade de São Paulo.

As imagens são referências fundamentais de pesquisa para o estilista que, no seu processo de criação, utiliza-se desse repertório visual articulando-o com o pensamento do designer, mediado pela afetividade e pela seleção natural dos seus registros. Essa discussão levou o GT Moda e Territórios de Existência: Processos de Criação e Subjetivação à seleção do instigante artigo Processo de criação do designer de moda André Lima: cartografando imagens-ilhas, de autoria de Yorrana Maia.

Assunto recorrente no nosso cotidiano ou uma frase com resposta pronta, o GT Ensino de Moda: Teoria e Prática discutiu uma questão bastante pertinente e diversa da bibliografia comum sobre o estudo do gosto, no interessante artigo Gosto se discute?, de Cyntia Tavares Marques de Queiroz, que, sobre uma abordagem histórica das teorias do currículo, recorta e apresenta uma investigação transdisciplinar sobre como a questão do gosto pode ser abordada no campo da moda.

Por outro lado, os trajes e acessórios são documentos essenciais para o estudo da história do vestuário e da moda, porém os trabalhos sobre acervos ainda são recentes no Brasil. 0 artigo As roupas pelo avesso: cultura material e história social do vestuário, de Maria Cristina Volpi, apresentou um importante projeto que vem sendo realizado desde 2005 pelo Centro de Referência Têxtil/Vestuário (CRTV) cujo objetivo é oferecer subsídios para o ensino e a pesquisa sobre a história da indumentária no Brasil, envolvendo a participação de estudantes de graduação e pós-graduação na organização de materiotecas e banco de imagens. Foi indicado pelo GT Moda, Cultura e Historicidade.

Também foram premiados artigos que tratam da questão da acessibilidade e sustentabilidade no campo da moda, vestuário e indústria têxtil, dentre estes, o artigo apresentado no GT Design e Processos de Produção de Moda, Antropometria e ergonomia no design para cadeirante desportista, de Maria do Socorro de Araújo e Miguel Ângelo Fernandes Carvalho, que aborda a importância da utilização da antropometria e ergonomia no design e modelagem do vestuário para pessoas com necessidades especiais motoras e em especial dos trajes de uma equipe de jogadores de basquetebol em cadeira de rodas da Associação Portuguesa de Deficientes (APD), Delegação Distrital de Braga, Portugal.

0 GT Moda, Sustentabilidade e Inclusão Social indicou o artigo Inovações em processos de impressão têxtil, de Felipe Guimarães, cujo objetivo é articular o conceito de inovação tecnológica incremental, especificamente em relação às técnicas analógicas e digitais de criação e produção de impressão têxtil, com vistas a discutir as transformações decorrentes das questões de sustentabilidade.

Na tentativa de "descer o pano" concluindo esta nossa apresentação, o GT Traje de Cena selecionou para esta edição especial o artigo Capitu: a televisão vestida em camadas, de Carolina Bassi de Moura, que propõe um diálogo entre o romance Dom Casmurro e a minissérie Capitu, exibida pela TV Globo, em uma afirmação de que a literatura machadiana é atemporal. Na sua abordagem universalizante, o escritor buscou desvendar as múltiplas facetas da alma humana, o que cumpriu como nenhum outro, explorando o contexto das aparências no fim do século XIX, com aguçada ironia, o que faz a linguagem estética proposta pela minissérie demonstrar o mesmo cenário na sociedade atual, libertando a obra das limitações de tempo e espaço. 
Além do melhor artigo de cada GT, nesse ano foi criado também uma Menção Honrosa para o trabalho Os termos de moda na Língua Brasileira de Sinais, de Aline Machado. 0 texto trata da relação entre moda e educação inclusiva e tem por objetivo propor a criação de um vocabulário técnico em Língua Brasileira de Sinais específico da moda com vistas a promover a articulação entre os alunos com deficiência auditiva e os das classes regulares nos cursos de Moda e Design de Moda. 0 trabalho foi selecionado em razão da originalidade e contribuição para a acessibilidade ao ensino de moda.

\section{NOTAS}

[1] A 1a Edição do Colóquio de Moda foi realizada no Centro Universitário Moura Lacerda por iniciativa das professoras Maria de Fátima Mattos e Kathia Castilho.

${ }^{[2]}$ Atualmente, existem dez Grupos de Trabalho em funcionamento no evento, os quais serão elencados no decorrer desta apresentação. Nos GTs apenas pesquisadores com titulação mínima de mestre podem apresentar trabalho, pesquisadores mestrandos ou graduados podem apresentar suas pesquisas em Sessões de Comunicação Oral e graduandos podem apresentar pôsteres.

${ }^{[3]}$ Em 2013, o Comitê Organizador do Colóquio de Moda era formado pela diretoria da Associação Brasileira de Estudos e Pesquisas em Moda (Abepem), composta pelos seguintes nomes: Profa. Dra. Kathia Castilho Presidente da Abepem; Profa. Dra. Maria de Fátima Mattos (CUML); Profa. Dra. Maria Claudia Bonadio (UFJF); Profa. Ms. Dorotéia Baduy Pires (UEL); Profa. Dra. Maria Carolina Garcia (Belas Artes/UAM); Profa. Dra. Mônica Moura (Unesp); e Profa. Dra. Ana Paula de Miranda (UFPE). Também colaborou para a instituição do prêmio a Profa. Ms. Cyntia Tavares (UFC), presidente do Comitê Organizador Local do evento.

${ }^{[4]}$ Vale lembrar que a tese de Gilda de Mello e Souza não foi a primeira a ter sido defendida sobre o tema no País. Em levantamento realizado em 2010 Maria Claudia Bonadio localizou na biblioteca da Universidade Federal do Rio de Janeiro (UFR) a tese de Virgílio Maurício da Rocha defendida na Faculdade de Medicina da Universidade do Brasil, em 1926, e intitulada Da mulher - proporções, beleza, deformação, hygiene e sport.

${ }^{[5]}$ A primeira edição brasileira é de 1989, mas o livro foi publicado na França em 1987.

${ }^{[6]} \mathrm{Em}$ 2010, havia 26 livros sobre moda e vestuário publicados e resultantes de dissertações e teses, o que é um indice importante para avaliar o crescimento na área. Mas, além desses, há também inúmeros livros de teor acadêmico produzidos por pesquisadores nacionais e internacionais disponiveis no mercado. Sobre o tema ver: Bonadio (2010) e Pires (2011). Importante lembrar que, além do Colóquio de Moda, desde 2008 outro evento que congrega pesquisadores da área de moda ocorre anualmente no Pais - o Encontro Nacional de Pesquisa em Moda - que, em 2013, teve sua $3^{a}$ edição nacional (até 2010 o evento era regional) realizada na Universidade Federal de Minas Gerais (UFMG). Vale ainda mencionar que em 2013 ocorreram também os seguintes eventos: A moda além da moda - cultura material e as múltiplas faces do vestir, realizado na Pontificia Universidade Católica do Rio Grande do Sul (PUCRS); o Congresso Internacional de Negócios da Moda, iniciativa do Instituto Brasileiro de Moda (IBModa), ambos mesclando apresentação de professores convidados para palestras com apresentação de comunicações orais. Atualmente, existem no Brasil pelo menos três revistas científicas mensuradas pelo Qualis da Capes e dedicadas ao tema moda, são elas: dObra[s] (impressa), lara:Revista de Moda, Cultura e Arte (on-line) e Modapalavra (on-line).

[7] Selecionamos a referida agência de fomento para essa amostragem, pois é a única que disponibiliza uma biblioteca que reúne informações sobre os projetos já financiados. Disponivel em: <http://www.bv.fapesp.br/pt/>. Acesso em: 23 nov. 2013.

${ }^{[8]}$ Se somado a esse montante o número de projetos que tem a palavra figurino em seu resumo ou palavra-chave, o total sobe para cerca de 130

\section{REFERÊNCIAS}

BONADIO, M. C. A produção acadêmica sobre moda na pós-graduação stricto sensu no Brasil. lara: Revista de Moda, Cultura e Arte, n. 3, v. 3, p. 50-146, 2010. Disponível em: <http://www.iararevista. sp.senac.br/arquivos/noticias/arquivos/141/anexos/pdf003.pdfs. Acesso em: 24 nov. 2013.

LIPOVETSKY, G. O império do efêmero: a moda e seu destino nas sociedades modernas. São Paulo: Companhia das Letras, 1989.

PIRES, D. B. Banco de referências de moda em língua portuguesa, versão Xl, 2011. Disponivel em: $<$ <ttp://www.designbrasil.org.br/sites/default/files/files/arquivos_usuarios/7471/Acervo_Referencias_ Moda_PT_XI_09-2011.pdf. . Acesso em: 24 nov. 2013.

PONTES, H. A paixão pelas formas: Gilda de Mello e Souza. Novos Estudos, n. 74, p. 87-105, mar. 2006. Disponivel em:<http://novosestudos.uol.com.br/v1/files/uploads/contents/108/20080627_a_paixao_ pelas_formas.pdf 7 . Acesso em: 24 nov. 2013. 